\title{
US radiation study sparks debate
}

\section{Researchers divided on how best to probe any possible link to cancer.}

\section{BY GWYNETH DICKEY ZAKAIB}

厂 in apan's ongoing nuclear emergency has intensified discussion on a simmering issue: the potential cancer risk from living near a reactor that is operating normally.

Last year, long before the crisis in Japan, the US Nuclear Regulatory Commission (NRC) asked the National Academy of Sciences (NAS) to examine this cancer question, prompted in part by long-standing public unease. The NAS is now consulting with experts about how to design a study, with the next public meetings on the effort scheduled for 18-19 April in Chicago, Illinois. Already, however, some researchers have questioned the study's feasibility and expressed doubt over whether it will produce meaningful results.

According to the NRC, less than $1 \%$ of a person's total annual background-radiation exposure comes from living near nuclear power plants. Much more comes from natural sources in the earth and air, and from some medical exams. Even so, "there are recurrent concerns among the public about increased cancer risks", says Terry Brock, the NRC's project manager for the Analysis of Cancer Risk in Populations Near Nuclear Facilities study. "We want the most current and most scientifically valid information to respond."

The last US-wide study, which found no evidence of a problem, was published by the National Cancer Institute in 1990. Now the NRC aims to update this effort by taking advantage of two decades of improvements in data and technology. For example, whereas the 1990 study considered only cancer deaths, better record-keeping means that researchers can

\section{"They may make the public feel better, but they'renot going to see very low-dose effects."} now look for suspect patterns in cancer diagnoses. The previous study also lumped people by county, regardless of their actual distance from a nuclear plant. Global positioning systems, which can pinpoint where people live in relation to a reactor, should now help provide more meaningful results. A further step would be including estimates of radiation doses and looking for correlations with cancer incidence.

But Edward Maher, president of the USbased Health Physics Society, says that even if the study takes all of those factors into account, its statistical power will be too low.

"We feel that those studies don't have a lot of value," says Maher. "They may make the

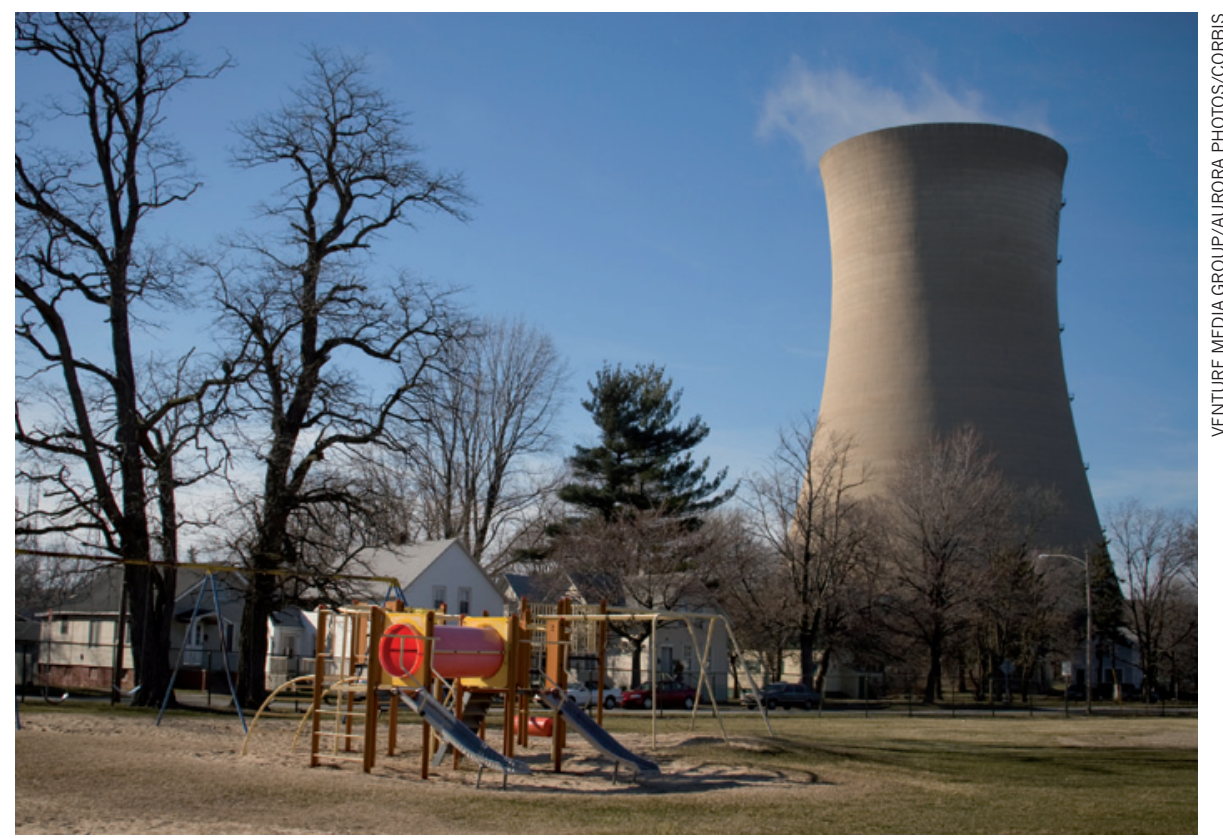

Some studies have found links between childhood cancer and proximity to power stations.

public feel better, but they're not going to see very low-dose effects." The money would be better spent on more laboratory research, he adds, where confounding factors such as the presence of other carcinogens can be effectively controlled.

Other experts say that the NAS should build on and improve a 2008 German study (C. Spix et al. Eur. J. Cancer 44, 275-284; 2008), which found a roughly 1.5 -fold increase in cancers in children younger than 5 living within 5 kilometres of nuclear power plants. The authors concluded that plant emissions were too low to explain the effect, and similar studies done later in France and Britain failed to show any cancer increase, but some researchers have challenged their interpretation of the data.

Nevertheless, Steve Wing, an epidemiologist from the University of North Carolina at Chapel Hill, says that if there is an effect, it will be easiest to see in children and fetuses. Their rapidly dividing cells make them more sensitive to radiation than adults, and they haven't been exposed to as many possible carcinogens. Wing and his colleagues wrote an article on how best to design the NAS study in the 1 April issue of Environmental Health Perspectives (S. Wing et al. Environ. Health Perspect. doi:10.1289/ehp.1002853; 2011). Among other things, they emphasize the need to obtain radiation-dose estimates for the populations under study.

In the upcoming April meetings, the NAS committee will discuss nuclear power plant emission monitoring and hear study design suggestions. After a series of additional meetings, the committee aims to complete recommendations by the end of 2011, after which they will be posted online for public comment. If the committee decides to move forward with the study, another committee will be appointed next year to carry it out.

Some experts think that there is no effect for the study to find. Antone Brooks, a radiation toxicologist at Washington State University Tri-cities in Richland, says that DNA repair mechanisms and selective suicide of damaged cells are adequate to handle DNA damage below a certain dose threshold.

"We've lived in a sea of radiation throughout evolution," says Brooks. "The body knows how to handle low doses."

Others believe that the risk never vanishes. DNA repair mechanisms don't work perfectly $100 \%$ of the time, and even small amounts of radiation confer some risk, says Bill Morgan, the director of radiation biology and biophysics at Pacific Northwest National Laboratory in Richland. "It's a tremendous debate," he says.

Some will argue that if no effect is found, there isn't a problem, says David Brenner, director of the Center for Radiological Research at Columbia University in New York. "But the fact that you can't measure a risk in an epidemiological study doesn't mean that the risk isn't there." - 